\title{
$\mathrm{Sc}$ 을 첨가한 $\mathrm{Al}-\mathrm{Zn}-\mathrm{Mg}-\mathrm{Cu}$ 합금 압출재의 열처리에 따른 미세구조 변화

\author{
이혜경* ${ }^{*}$ 서동우 ${ }^{*}$ 이상용* 이경환 ${ }^{* *}$. 임수근 ${ }^{* *}$
} \\ (2003년 10월 9일 접수)
}

\section{Microstructural Characterization of Hot Extruded Al-Zn-Mg-Cu Alloys Containing Se}

\author{
H. K. Yi, D. W. Suh, S. Y. Lee, K. H. Lee and S. G. Lim
}

\begin{abstract}
The microstructural changes of $\mathrm{Al}-\mathrm{Zn}-\mathrm{Mg}-\mathrm{Cu}$ alloy containing Sc during hot extrusion and post heat treatment were investigated. Two kinds of Al-Sc alloys with different alloying elements (B1, B2) were hot extruded to make T-shape bars at extrusion temperature of $380^{\circ} \mathrm{C}$, then the bars were solution treated at $480^{\circ} \mathrm{C}$ for $2 \mathrm{hrs}$ followed by artificial aging at $120^{\circ} \mathrm{C}$ for $24 \mathrm{hrs}$. The interior microstructure of as extruded bar consisted of elongated grains, however, fine equiaxed grains were also observed around surface. The microstructural gradient suggested that different restoration process could proceed during the hot extrusion. For B1 and B2, different grain growth behaviors were found around the surface during the post heat treatment. Rapid grain growth behavior was observed for B1 around the surface, however, it was not observed for B2. Orientation pinning, which was related with the evolution of preferred orientation, and precipitation were thought to be responsible for the rapid grain growth.
\end{abstract}

Key Words : Scandium, Hot Extrusion, Recrystallization, Abnormal Grain Growth

\section{1. 서 론}

$\mathrm{Sc}$ 이 첨가된 알루미늄 합금은 1970년대에 러 시아에서 개발되었으며, 이후 합금성분의 조정을 통한 개량이 이루어져 1990년도에 본격적으로 상 용화가 이루어졌다. ${ }^{(1 \sim 3)} \mathrm{Al}-\mathrm{Sc}$ 합금은 야구배트, 골프샤프트, 연료튜브 등에 적용된 바 있으며 최 근에는 특히 고강도가 요구되는 항공기용 부품에 적용하고자 하는 연구가 활발히 진행되고 있다. 7000 계열 합금에 소량의 $\mathrm{Sc}$ 을 첨가함으로써 강
도와 열적 안정성 뿐만 아니라 용접성 향상의 호 과를 얻을 수 있는 것으로 알려지고 있는데 ${ }^{(1)}$, 이 것은 주로 $\mathrm{Al}_{3} \mathrm{Sc}$ 석출물이 강도의 증가와 재결정 억제의 중요한 역할을 하기 때문인 것으로 보고 되고 있다. ${ }^{(4)}$ 지금까지 $\mathrm{Sc}$ 첨가 $\mathrm{Al}$ 합금의 연구는 주로 냉간 압연된 상태에서의 $\mathrm{Al}_{3} \mathrm{Sc}$ 석출 및 기 지의 재결정 거동에 관한 내용이 주를 이루고 있 으며 ${ }^{(5-6)}$ 산업적인 측면에서 볼 때 중요하다고 생 각되는 고온가공 공정과 이에 따른 후속 열처리 중의 미세구조의 변화에 대한 연구는 아직 미흡한

* 한국기계연구원 공정연구분

** 보원경근속우

**** 경상대학교 는속재토ㄹㅗㅗㅇ학과 
실정이다.

따라서 이 연구에서는 소량의 $\mathrm{Sc}$ 가 첨가된 7000 계 알루미늄 합금에 대하여 열간압출 공정에 따른 압출재의 미세구조 변화를 살펴보고 후속 열처리시의 표면 결정립 성장 거동에 대하여 고 찰해보고자 하였다.

\section{2. 실험방법}

본 연구에 사용된 합금은 7000 계열 알루미늄 합금의 주된 첨가 원소인 $\mathrm{Al}-\mathrm{Zn}-\mathrm{Mg}-\mathrm{Cu}$ 를 기본으 로 하여 $\mathrm{Sc}$ 을 $0.1 \mathrm{wt} \%$ 함유한 고강도 알루미늄 합 금으로서 Table 1 에 나타낸 것과 같이 $\mathrm{Zn}$ 및 $\mathrm{Cu}$ 의 합금 원소량을 변화시킨 두 가지 종류의 소재를 사용하였다. 압출은 빌렛을 $380^{\circ} \mathrm{C}$ 에서 1 시간동안 유지한 후 압출비 38:1 로서 T 형상 압출재를 직접 압출하였다. 이 때 압출 속도는 $0.017 \mathrm{~mm} / \mathrm{s}$ 로 하였 다. 압출재의 형상을 Fig. 1 에 나타내었다.

Table 1 Chemical composition of test alloy (wt\%)

\begin{tabular}{c|c|c|c|c|c|c|c|c}
\hline & $\mathrm{Zn}$ & $\mathrm{Mg}$ & $\mathrm{Cu}$ & $\mathrm{Cr}$ & $\mathrm{Zr}$ & $\mathrm{Mn}$ & $\mathrm{Sc}$ & $\mathrm{Al}$ \\
\hline $\mathrm{B1}$ & 7.9 & 2.0 & 1.9 & 0.03 & 0.11 & - & 0.1 & Bal. \\
\hline $\mathrm{B} 2$ & 5.2 & 2.0 & 0.3 & 0.03 & 0.11 & 0.3 & 0.1 & Bal \\
\hline
\end{tabular}

열간압출된 압출재를 $480^{\circ} \mathrm{C}$ 에서 2 시간동안 용 체화 처리하고 $120^{\circ} \mathrm{C}$ 에서 24 시간동안 시효처리하 여, 압출직후와 열처리 후의 미세조직 변화를 관 찰하였다. 관찰부위는 직접압출 중 변형을 가장 많이 받은 끝부분과, 압출재의 중간부위를 중심부 터 표면까지 세부분으로 나누어 관찰하였다. 압출 재의 미세구조는 광학현미경과 EBSD (Electron Back Scattered Diffraction) mapping 을 이용하여 분 석하였다.

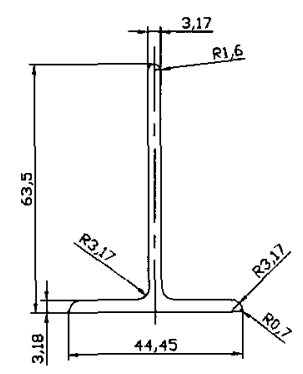

Fig. 1 The shape and dimension of extruded bar

54 /한국소성가공학회지/제 13 권 제 1 호, 2004 년

\section{3. 실혐결과 및 고찰}

3.1 압출전 원소재의 미세구조

압출직전의 미세구조를 평가하기 위하여 $380^{\circ} \mathrm{C}$ 에서 1 시간 유지시킨 후 수냉한 빌렛의 미세조직 을 Fig. 2에 나타내었다. 각 시편의 평균 결정립 크기는 약 $100 \mu \mathrm{m}$ 정도였으며, 두 시편 모두에서 입자내부에 미세한 석출물이 분산되어 있음을 볼 수 있었다. B2의 경우, $\mathrm{B} 1$ 에 비하여 석출물의 양이 상대적으로 작은 것으로 관찰되었는데, 이것은 $\mathrm{B} 2$ 가 $\mathrm{B} 1$ 에 비해 합금 원소 첨가량이 작기 때문으로 생각된다.

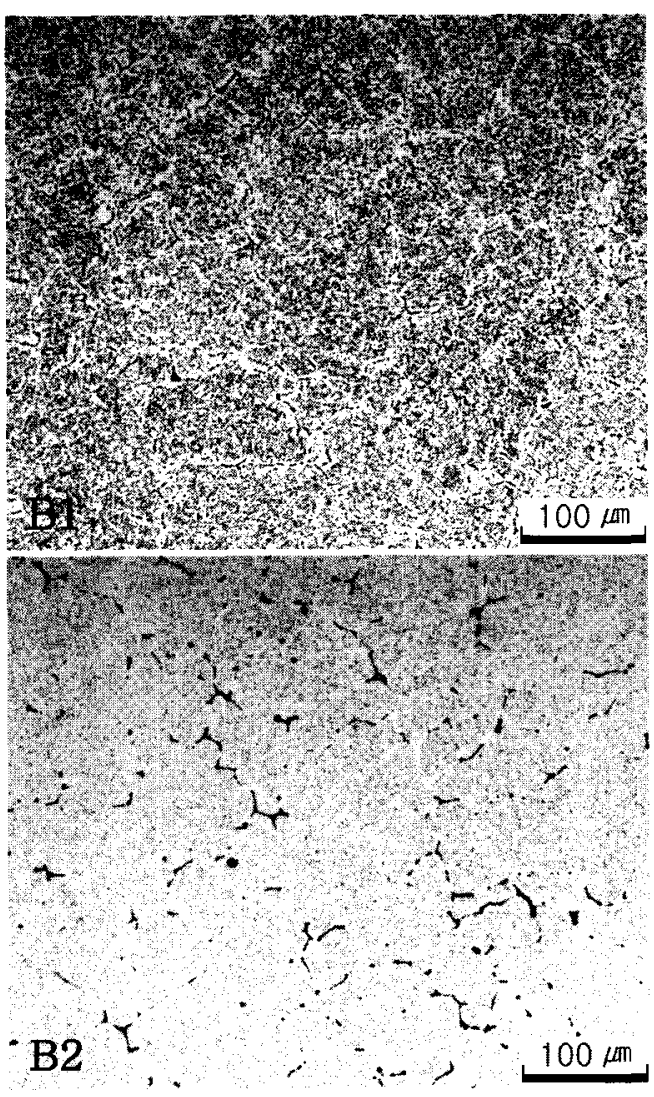

Fig. 2 Microstructure of billet before hot extrusion

\section{2 압출재의 압출직후 미세구조}

열간압출 직후 압출재의 미세조직을 Fig. 3과 Fig. 4 에 나타내었다.

알루미늠의 경우에는 열간 변형 후 회복이 일 어나면 일반적인 금속현미경에서는 입계를 구별 하기 어렵게 된다. 이러한 경우 편광현미경을 이 
용하여 결정립 형상을 관찰할 수 있지만 본 연구 에서는 결정립의 방위에 따라 미세구조를 maping 할 수 있는 EBSD (Electron Back Scattered Diffraction) 를 이용하였다. EBSD를 통하여 관찰되는 이미지 는 각각의 결정립을 결정방위에 따라서 mapping 한 이미지로서 적정한 어굿남각 조건에 의하여 결정립의 형상을 이미지화 할 수 있다. 본 연구에 서는 양쪽방향의 결정립 방위가 $5^{\circ}$ 이상 차이가 나는 경우에 서로 독립적인 결정립으로 간주하여 결정립의 형상을 이미지화 하였다.

압출재의 미세구조는 Fig. 3 와 Fig. 4 에서 보는 바와 같이 결정립의 형태가 압출재의 중심부에서 표면쪽으로 갈수록 길게 연신된 형태에서 점점 등축정의 형태로 변화되는 것으로 나타났다.

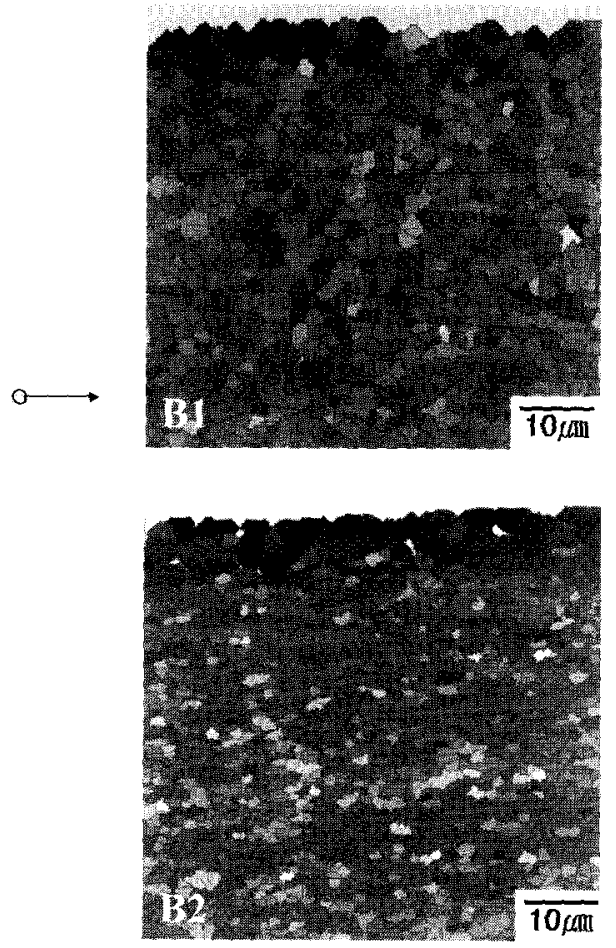

Fig. 3 Microstructures of hot extruded bar (top head)

압출재 중심부에 나타낸 연신된 결정립은 열간 압출 도중에 일어나는 연화과정(restoration process) 이 주로 동적회복임을 나타내지만 압출재 표면에 서 주로 관찰되는 등축상의 미세 결정립들은 열 간 압출시의 동적 회복과정만으로는 형성되기 어 려운 것으로 알려젹 있다. 일반적으로 소성가공공
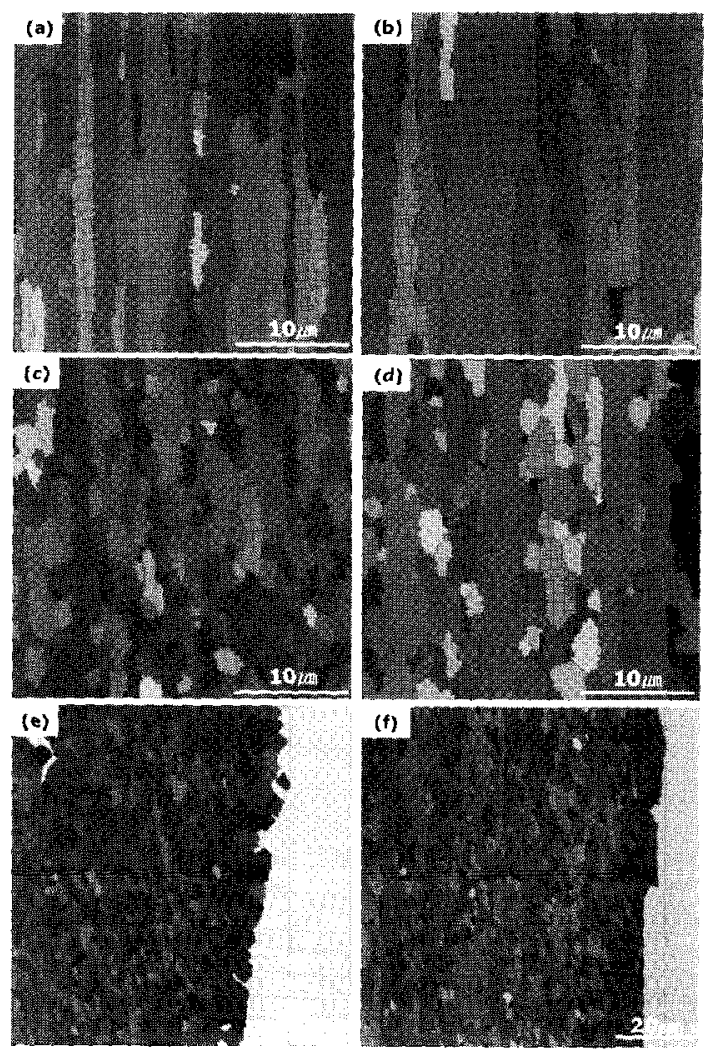

$\begin{array}{lll}\text { (a) } \mathrm{B} 1 \text {, center } & \text { (c) } \mathrm{B} 1 \text {, intermediate (e) B1, surface } \\ \text { (b) B2, center } & \text { (d) B2, intermediate (f) B2, surface }\end{array}$

Fig. 4 Microstructures of hot extruded bar

정 중 동축상의 결정립이 형성될 수 있는 경우는 다음의 세가지로 구분할 수 있다. (7 9)

(i) Discontinuous dynamic recrystallization (불연속 재결정)

(ii) Continuous recrystallization (연속재결정)

(iii) Geometric recrystallization (기하학적 재결정)

$\mathrm{Al}$ 합금과 같이 적층결함 에너지가 높은 금속 에 있어서는 불연속 재결정은 거의 간찰하기 어 려운 것으로 알려지고 있으므로 Fig 3 과 Fig. 4 에 서 나타난 것과 같이 압출재의 표면부에서 관찰 되는 둥축상의 결정립들은 연속재결정 또는 기하 학적 재결정에 의해서 형성되는 것으로 생각된다. 일반적으로 연속재결정이나 기하학적 재결정은 재로가 좊은 변형률로 심하게 가공되었을 겅우에 변형된 결정립 내부에서의 전위 재배열과 결정립 계로의 전위의 흡수 또는 결정립계의 상호접촉 (interpenetration of serrated boundary)에 의하여 일어 
나는 것으로 알려지고 있다. 본 연구에서와 같은 높은 압출비와 압출재와 금형간의 마찰에 의한 전단변형에 의해 압출재 표면부의 변형률이 증가 하게 되면 압출재 내부로부터 포면부에 걸쳐서 유효변형률의 구배가 존재하게 되고 이러한 유효 변형률의 구배에 의해 압출재 포면부에 미세한 등축상의 결정립과 내부에 연신된 결정립이 동시 에 형성될 수 있을 것으로 생각된다.

\section{3 압출재의 열처리 후 미세구조}

압출재의 특성을 극대화하기 위한 $\mathrm{T} 6$ 열처리를 한 후 미세구조 변화를 Fig. 5 와 Fig. 6 에 나타내 었다. Fig. 5 는 T6 열처리 후 압출재의 광학현미경 사진으로서 Bl 의 경우 압출재의 표면부에 결정 립 성장층이 나타나고 있음을 알 수 있다.

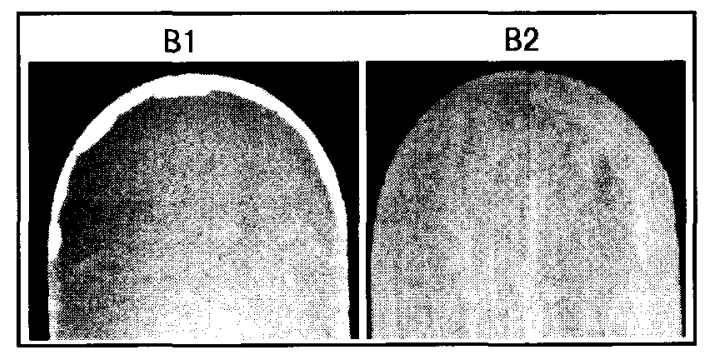

Fig. 5 Macrostructures of hot extruded bar after heat treatment

이에 반하여, B2의 경우에는 열처리 후에도 별 다른 미세구조상의 변화를 관찰할 수 없었다. 표 면 결정립 성장층을 보다 자세하게 관찰하기 위 하여 EBSD mapping을 통하여 압출재의 표면부 를 관찰한 결과를 Fig. 6에 나타내었다. Fig. 3에 나 타낸 압출 직후의 미세조직과 비교해볼 때 $\mathrm{B} 1$ 의 경우 표면부에 급속한 결정립 성장이 이루어진 것을 알 수 있다. 초기의 미세한 결정립의 크기가 약 2 $3 \mu \mathrm{m}$ 정도인 것에 비하여 열처리 과정 중 급 속히 성장한 결정립들은 크기가 약 $100 \mu \mathrm{m}$ 정도에 이르도록 성장하였다. 열처리 시간별 결정립의 성 장 양상을 확인하기 위하여 $\mathrm{B} 1$ 압출재를 각각 15 분, 30 분 그리고 60 분 동안 $480^{\circ} \mathrm{C}$ 에서 용체화 처 리한 후 관찰한 미세조직과 압출방향으로의 결정 립들의 방위분포를 Fig. 7에 나타내었다. 그림에서 알 수 있듯이 용체화 처리 중 몇몇 결정립들이 주위의 미세한 등축상 결정립들을 잠식하며 압출 재의 표면에서부터 내부로 급속히 성장하고 있다.

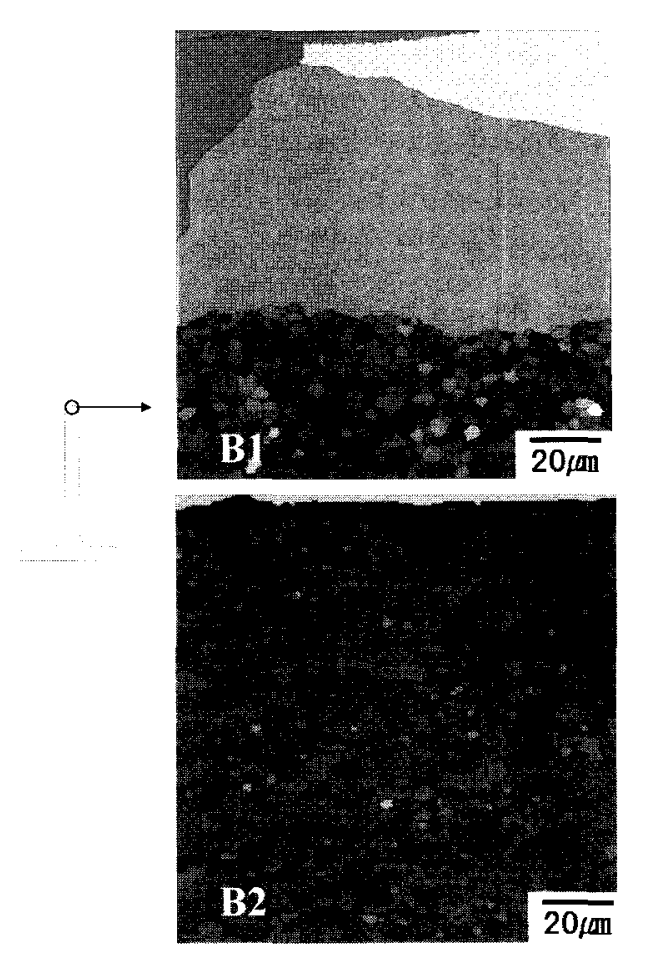

Fig. 6 Microstructures of hot extruded bar after heat treatment

이러한 표면부 결정립의 급속한 성장에서 매우 흥미로운 사실은 급속히 성장하는 결정립의 대부 분이 초기 미세 결정립들의 주된 결정방위와 다 른 결정방위를 가진다는 것이다. Fig. 7 에 나타낸 것과 같이 열처리 후 미세 결정립들의 주된 방위 는 $<100>$ 과 $<111>$ 이 압출방향에 평행한 방위로서 신선된 면심입방금속이 가공 후 또는 어널링 후 에 나타내는 결정방위로 잘 알려져 있다. ${ }^{(10)}$ 그에 반해서 급속한 성장이 일어난 결정립의 방위는 주로 $<110>$ 방위가 압출 방향에 평행한 방위들이 다. 이러한 방위들은 열간압출 직후의 미세 결정 립에서는 거의 관찰되지 않지만 용체화 처리 도 중에 급속히 성장하는 것으로 관찰되었다. 최근에 신선된 Al 선재에서도 비정상 성장된 < $110>$ 결정 립들이 관찰된다는 결과가 보고되는 것으로 보아 (11) 이러한 표면 결정립 성장 거동은 결정립의 방 위와 관련이 있는 것으로 생각된다. 즉 강한 우선 방위가 발달된 영역에서 우선방위 주변의 결정방 위를 가지는 대다수의 결정립들은 주위의 결정립 들과 낮은 어긋남각(misorientation)을 가질 확률이 높으며 따라서 결정립간의 계면 에너지가 낮아 결 


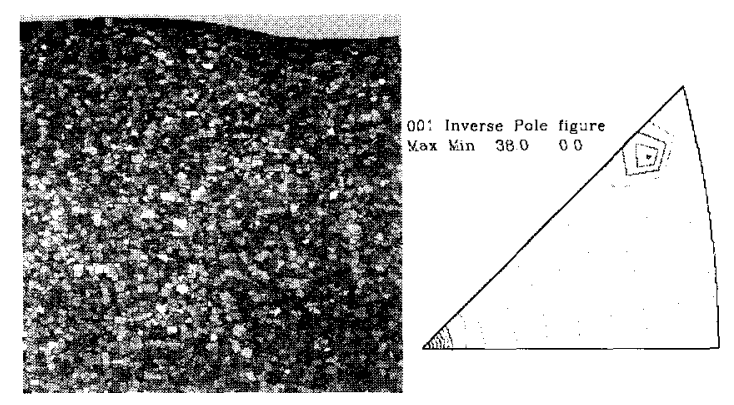

(a) Solution treated for $15 \mathrm{~min}$, IPF of fine grains
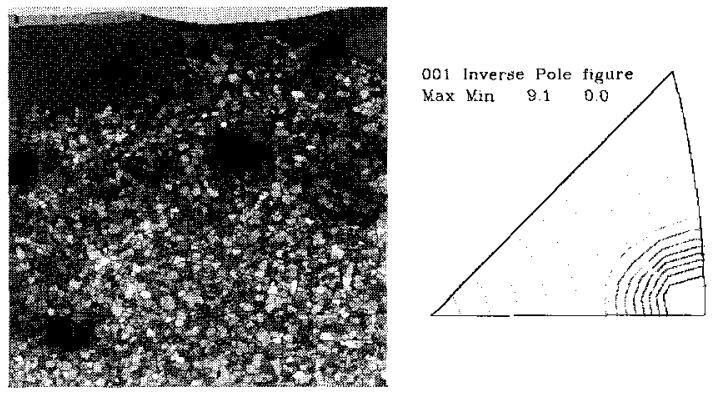

(b) Solution treated for 30min, IPF of large grains

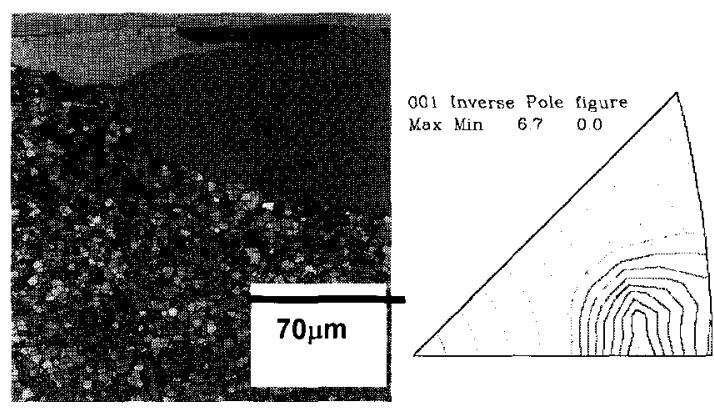

(c) Solution treated for $60 \mathrm{~min}$, IPF of large grains

Fig. 7 Microstructures and inverse pole figure of solu -tion treated bar (B1)

정립계의 이동도도 낮아지는데 반해 우선 방위와 다른 방위를 가지는 결정립은 주위 결정립과의 어긋남각이 크기 때문에 이러한 결정립의 계면은 대부분의 다른 결정립 계면에 비하여 상대적으로 높은 이동도를 가질 수 있게 된다. 그러나 결정립 들의 우선방위의 분포가 $\mathrm{B} 1$ 과 거의 유사한 것으 로 분석되어진 $\mathrm{B} 2$ 에서는 표면 결정립의 급속한
성장이 관찰되지 않는 것으로 보아 결정립의 방 위 분포만이 성장거동을 지배하지는 않는 것으로 판단된다. 아직 명확하지는 않지만 B1과 B2의 가 장 큰 차이점이 합금원소의 함량의 차이인 것을 고려하면 용체화 처리중의 석출물의 거동 또한 압출재 표면부의 결정립 성장 거동에 영향을 미 치고 있을 것으로 생각된다.

\section{4. 결 론}

본 연구에서는 $\mathrm{Sc}$ 을 첨가한 $\mathrm{Al}-\mathrm{Zn}-\mathrm{Mg}-\mathrm{Cu}$ 합금 을 열간 압출하고 그 압출재를 열처리하여 미세 구조 변화를 관찰하여 다음과 같은 결론을 얻을 수 있었다.

(1) 압출직후의 미세조직은 변형방향으로 연신 된 결정립과 미세한 등축상의 결정립으로 이루어 져 있었다. 둥축상의 결정립들은 크기가 약 2 3 $\mu \mathrm{m}$ 수준의 매우 미세한 결정립들로서 주로 압출 재 표면부에서 관찰되었다.

(2) 열간 압출재 내부에서 주로 관찰되는 연신 된 결정립은 압출시의 주된 연화과정이 동적회복 임을 의미하지만 압출재의 표면부의 등축상 미세 결정립은 일반적인 동적회복과정에 의해서 형성 되기 어려우며 압출시 마찰에 의해 압출재 표면 에 발생하는 고변형부에서의 연속재결정 또는 기 하학적 재결정 과정에 의해 형성된 것으로 판단 된다.

(3) B1 의 경우 압출 후 열처리과정에서 표면부 의 급속한 결정립 성장이 관찰되었다. 압출재의 압출방향으로의 우선방위가 $<100>,<111>$ 이 주로 발달하는 것에 반하여 급속한 성장이 이루어진 결정립들은 주로 압출방향으로의 결정방위가 $4110>$ 인 것으로 분석되었다. 압출 후 열처리과정에서 의 결정립 성장은 이러한 우선방위의 형성에 의 한 일부 결정립계의 상대적으로 높은 이동도와 석출물의 영향에 기인한 것으로 생각된다.

\section{후 기}

본 연구는 산업자원부의 항공우주기술개발사업 의 지원으로 이루어졌으며 이에 감사 드립니다. 또한 고분해능 EBSD 분석에 도움을 주신 서울대 학교 이후철 교수님과 오규환 교수님께 감사 드 립니다. 


\section{참 고 문 헌}

(1) B. Lenczowski, R. Rauh, D. Wieser, G. Tempus, G. Fisher, J. Becker, K. Folkers, R. Braun and G. Lutjering, 2000, "Welable AlMgSc alloy for transportation technology", Aluminium, Vol. 76, pp. 200 203.

(2) A. F. Norman, P. B. Prangnell and R.S.McEwen, 1998, "The solidification behavior of dilute aluminium-scandium alloys", Acta Mater. Vol.46, pp. 5715 5732.

(3) L. S. Torpova, D. G. Eskin, M. L. Kharakterova and T. V. Dobatkina, 1998, "Advanced aluminum alloys containing $\mathrm{Sc}$ ", golden and Breach Science Publisher, Amsterdam.

(4) V. Ocenas and M. Slamova, 2001, "Resistence to recrystallization due to $\mathrm{Sc}$ and $\mathrm{Zr}$ addition to $\mathrm{Al}$ Mg alloys", Materials Characterization, Vol. 47, pp. 157 162.

(5) D. N. Seidman, E. A. Marquis and D. C. Dunand, 2002, "Precipitation strengthening at ambient and elevated temperatures of heat-treatable $\mathrm{Al}(\mathrm{Sc})$ alloys", Acta Mater., Vol.50, pp. 4021 4035.
(6) M. J. Jones and F. J. Humphreys, 2003, "Interaction of recrystallization and precipitation : The effect of $\mathrm{Al} 3 \mathrm{Sc}$ on the recrystallization behavior of deformed aluminum", Acta Mater., Vol.51, pp. 2149 2159.

(7) S. Gourdet and F. Montheillet, 2000, "An Experim -ental study of the recrystallization mechanism during hot deformation of aluminum", Mat.Sci. Eng., Vol. A283, pp. 274 288.

(8) D. W. Suh, S. Torizuka, A. Ohmori, T. Inoue and K. Nagai, 2002, "Dynamic restoration process of $\mathrm{Ni}$ $30 \mathrm{Fe}$ alloy during hot deformation", ISIJ International, Vol.42, pp. 432 439.

(9) S. I. Kim and Y. C. Yoo, 2002, "Continuous dynamic recrystallization of AISI430 ferritic stainless steel", Met. \& Mat. Int., Vol.8, pp. 7 13.

(10) F. J. Jumphreys and M. Hatherly, 1995, "Recrystall -ization and related annealing phenomena", Pergamon, Oxford.

(11) H. Park and D. N. Lee, 2001, "Deformation and annealing textures of drawn Al-Mg-Si alloy tubes", J. Mat. Proc. Tech., Vol.113, pp. 551 555. 